\title{
Françoise Collin - marcos de seu itinerário, projeto e alcance internacional ${ }^{*}$
}

Christiane Veauvy**

Françoise Collin faleceu no dia $1^{\circ}$ de Setembro de 2012, na Bélgica, onde nasceu em 1928. No início dos anos 2000, comentou publicamente seu desejo de ser reconhecida como "uma mulher em filosofia" (Collin, 2011), embora fosse conhecida, desde sua instalação em Paris (1981), como feminista e filósofa, diretora dos Cahiers du Grif (Groupe de recherches et d'informations féministes). Tal desejo se devia, provavelmente, a suas convicções, incertezas, talvez decepções; em todos os casos, às vicissitudes do seu percurso atípico, ultrapassando qualquer forma de classificação. Como testemunho disso, temos a contribuição de Mara Montanaro e Sylvia Duverger inscrita no primeiro livro em homenagem a ela:

(...) Françoise Collin não nasceu nem do feminismo, nem com o feminismo. Contrariamente à maioria das feministas chamadas "da segunda onda", sua aventura política $e$ intelectual não começou com o movimento. Quando entra no feminismo, já havia publicado poesias (1958), dois romances na coleção de Jean Cayrol na editora Seuil (1960 e 1963) e, pela editora Gallimard, seu renomado Maurice Blanchot et la question de l'écriture (1971). Este primeiro ensaio

* Recebida em 23 de abril 2016, aceita em 16 de agosto de 2016. Tradução do inédito em francês por Cristina Veauvy, Jean-Marie Veauvy e Néri de Barros Almeida.

** Professora Honorária do Centre National de la Recherche Scientifique (CNRS), Paris, França. veauvy@msh-paris.fr 
filosófico consagrado a Blanchot é, ainda hoje, uma obra de referência (Duverger; Montanaro, 2014). ${ }^{1}$

Em 1973, depois de ter descoberto o feminismo radical nos Estados Unidos e a existência de grupos de autoconsciência, Collin fundou com outras mulheres, em Bruxelas, onde residia, Les Cahiers du Grif - segundo opinião bastante difundida, a melhor revista feminista francófona- que dirigiu e organizou até o seu fechamento: ${ }^{2}$

(...) a articulação de um espaço plural passou a importar mais do que a elaboração de uma trajetória teórica singular, e mesmo fraturou ou reinterrogou aquela que eu tinha esboçado até então. Neste contexto é a questão que precisa ser elaborada e que importa mais do que a resposta. Se posso definir essa tarefa como constitutivamente política pois constitutiva de um 'mundo comum' (segundo expressão emprestada à $\mathrm{H}$. Arendt) - é no sentido de uma política das singularidades, sempre destotalizada. Pois é próprio desta política, que na perseguição de seus objetivos coletivos, ela se sustentasse (e se sustenta) apenas sobre uma conversão singular, que desloca a fronteira do privado $e$ do público redefinindo-os de maneira nova (Collin 2004:49-50).

Ela nos faz, assim, entrar em sua procura "constitutivamente política" e sublinha mais a elaboração da questão do que a resposta - uma prática iniciada com os Cahiers du Grif (primeira série, 1973-1978) que permanece subjacente a seu pensamento, a seus escritos dispersos pelo mundo, a suas intervenções espalhadas, enquanto ela ainda tinha força, por tantas localidades: no mundo francófono (Bélgica, França, Suíça, Quebec), na

1 Todas as citações foram vertidas pelos tradutores a partir de sua menção em língua original feita pela autora da resenha.

2 A coleção completa dos Cahiers (três séries: 1973-1978, 24 números; 19821993, 23 números; 1995-1997, 3 números) está disponível para consultas no site Persée. 
Europa do Sul (Itália, Espanha), no Norte de África (Tunísia), no Oriente Médio (no Líbano ao qual ela dedicou, em 1990, um número do Cahiers du Griff, na África, na América do Sul (Argentina, Brasil).

A partir de meados dos anos 1980, ela retorna à filosofia dedicou várias obras a $\mathrm{H}$. Arendt, da qual fora uma das introdutoras na França -, sem abrir mão da linha condutora da experiência dos Cahiers e sua relação com o feminismo. Assim, diz em conversa de 2001 com Florence Rochefort e Danièle HaaseDubosc:

Uso de bom grado o conceito de práxis, encontrado no marxismo, mas também presente em Arendt, em sua referência a Aristóteles, para designar ao mesmo tempo o pensamento e a prática (...) é verdade que o caráter emocionante do feminismo era e ainda está para mim, conectado com este primeiro projeto: desenhar a paisagem da liberdade, em vez de definir os seus objetos. A insurreição ou, se preferir, a desconstrução em vez da instituição (Haase-Dubosc; Rochefort, 2001:195-210).

Ela imprimiu uma dinâmica particular ao pensamento feminista, não só por suas obras, seus escritos, suas intervenções públicas, mas também pela troca de experiências que ela estabeleceu com tantas mulheres (feministas ou simpatizantes) e às vezes com homens, na França, Bélgica, Quebec, e em muitos países não francófonos.

As duas obras publicadas em francês em 2014 (Collin, 2014; Azzoug; Veauvy, 2014) ${ }^{3}$, a que se dedica este texto, têm como origem duas iniciativas geograficamente distantes. Elas diferem quanto a seu objeto, seu conteúdo e suas formas de elaboração, guardando uma e outra um lugar para a memória viva que têm os autor-as-es dos debates e das emoções vividas com Françoise Collin.

3 Além dessas, também foi publicado um compêndio de textos em espanhol (Collin, 2006). 
A Anthologie québécoise 1977-2000 é o resultado de um projeto longamente amadurecido por Marie-Blanche Tahon. Ninguém melhor qualificada do que essa feminista, professora de sociologia na Universidade de Ottawa, "oriunda do Quebec, sem origem desde 1980" (p. 17), para reunir e apresentar textos que compõem esse volume. Muitos deles são respostas a solicitações feitas por feministas para conferências acadêmicas (Françoise Collin foi convidada várias vezes pelas universidades de Ottawa, de Montreal, de Laval, e de Québec) ou para seminários organizados por grupos de pesquisa não institucionais, tal como o Centre d'études multidisciplinaires et d'informations féministes (CEMIF, Montreal). Outros foram escritos por iniciativa de Françoise Collin. Anthologie também inclui entrevistas, publicadas inicialmente em diferentes revistas, além do prefácio que escreveu ao livro de Diane Lamoureux (Collin, 1986:109-116).

$\mathrm{O}$ vigor e a riqueza do feminismo no Québec, sua criatividade entre os anos 1970 e 1990, aparecem nas referências editoriais dos textos da Anthologie, dezesseis dos quais são devidos à Françoise Collin e um à Suzanne Lamy (Lamy, 1985:8386) - uma amiga feminista prematuramente falecida e que (fato excepcional!) procurou remediar o obscurecimento do "trabalho criativo e crítico Françoise Collin", em razão de suas funções no Cahiers du Grif. Esta última havia dito, logo após o falecimento da amiga: "Estamos sempre deslumbradas com a situação no Quebec. Aqui o feminismo é em ato: é parte da vida cotidiana, na mídia, na política, na universidade, e é reconhecido por toda a sociedade como inevitável" (Collin, 1988:140).

Ao emprestar o título de seu prefácio - "Não há liberação sem liberdade" - à Françoise Collin, Marie-Blanche Tahon lembra a amiga quando acolheu com um sorriso a dedicatória do primeiro volume das atas do $4^{\circ}$ Congresso Internacional Pesquisa feminista em francofonia plural, Des frontalières (2007): "À Françoise Collin, sem a qual o feminismo seria menos plural". Ela explica essa dedicatória como expressão da dívida que reconhece ter contraído com Françoise Collin "e que nela permanece sempre". Após anunciar a cronologia dos textos, ela se contenta 
em dizer, com (demasiada) modéstia, que se ocupará "em destacar alguns elementos do pensamento de Collin suscetíveis de nos fazer pensar e questionar a prova pela qual atualmente passam a sociedade e os feminismos do Quebec" (p. 8). A relação entre teoria e prática (praxis) está no coração de sua jornada.

O feminismo é para Françoise Collin ao mesmo tempo, o último avatar do mundo moderno e o sintoma do que vamos chamar aqui, por falta de um termo melhor, e ao abrigo de sua imprecisão, o mundo pós-moderno (p. 9, tirado de seu prefácio ao livro de Diane Lamoureux). Em meados dos anos 1980, "um mundo se abalou": Estava-se então, no interstício entre o moderno e o pós-moderno e, provavelmente, em 2014, ainda estamos (...).(p. 15).

Collin "não pensa em termos de uma lógica de opostos" (p. 10) - por exemplo, "não há cogito-mulher", em que ela coloca em questão "a cultura no feminino" - "uma hipótese", nessa cultura

se encontram famílias de espírito, tendências, práticas diversas. Não podemos esquecer que uma cultura que aplaina singularidades é uma ditadura. E o fanatismo do "coletivo" tornou-se a máscara desta ditadura (p. 43).

A escrita incisiva de Collin ecoa o feminismo do Quebec. Em um país que ainda não é completamente um, segundo Marie-Blanche Tahon, há em sua língua materna uma liberdade de fala mais ofensiva do que na França ou na Bélgica.

Collin "é sem dúvida a primeira a sublinhar, com Arendt, que a condição humana é pensável não apenas como mortal, mas primeiramente e, antes de tudo, como natal", escreve MarieBlanche Tahon (Collin, 2014:12-13) referindo-se a condição do homem moderno em Arendt $e$ ao texto de Collin "A condição natal" (Collin, 2014:47-67), resultante de um colóquio internacional realizado na Universidade de Montreal (VIIIe Colloque interdisciplinaire de la société de philosophie du Québec, 1984). 
(...) a verdadeira igualdade não é a partilha de direitos e de bens definida unilateralmente, defende Collin, mas a partilha da condição de sujeito ético, político, histórico, isto é, a possibilidade para mulheres, para cada mulher, de não serem apenas beneficiárias de vantagens e desvantagens sociais, mas também, e sobretudo, de serem reconhecidas em sua posição original, geradora, posição que toda a história lhe negou, reduzindo nela a força do começo à maternidade estritamente biológica (Collin, 2014:12-13)

Na apresentação ao livro de Françoise Collin, Marie-Blanche Tahon afirma sua originalidade sobre esse tema (a igualdade) em termos bastante diferentes daqueles que utilizou na França. Tahon introduz com fineza, sutileza e sobriedade outros elementos de seu pensamento (história das mulheres, linguagem, escrita, etc.), sem negligenciar qualquer aspecto, numa abordagem complexa (Collin, 2014:7-18). Anthologie québécoise é a segunda coletânea de Françoise Collin a ser publicada em francês. A primeira, intitulada Je partirais d'un mot. Le champ symbolique foi preparada em 1999 por Carmen Boustani (Editions Fus Art). Dois textos são comuns às duas coleções: "Il n'y a pas de cogito femme" e "La marque et la trace" - este título tornou-se no l'Anthologie québécoise "Histoire et mémoire ou la marque et la trace", certamente para introduzir uma versão ligeiramente diferente da anterior. Françoise Collin tinha realmente o hábito de remanejar seus textos várias vezes. Essas duas coleções têm raízes local, política, feminista; elas incitam a aprofundar as questões urgentes que a autora levantou com sua lucidez habitual - por exemplo, sobre o social e dos laços sociais, afirma a partir de sua leitura de Lévinas: "constituir um laço dito social é abrir espaço ao incomensurável". ${ }^{4}$ Pode-se ouvir aí um apelo (aos práticos-as da sociologia, da história social, da antropologia) para a construção em outros termos das ciências sociais; Françoise Collin se aproxima aqui de Alain Touraine (2013), por outros caminhos.

4 Ver "La condition natale" (2014:47-67) . 
Enquanto se aguarda a publicação de coletâneas que ela mesma começou e que não teve tempo de terminar, o confronto do que temos define o tom na direção de um novo registro: saída do confinamento no nacionalismo, apelo à construção das ciências sociais de uma outra forma, renovação da abordagem feminista a partir da problemática Norte/Sul, oposição que se encontra ela mesma transformada, etc.

Françoise Duroux, filósofa feminista que morreu em janeiro de 2015, abre o caminho com sua contribuição ao trabalho coletivo em homenagem à Françoise Collin, Femmes, genre, féminismes en Méditerranée. "Le vent de la pensée". Intitulado "Féminismes du Nord, féminismes du Sud en Europe", esse texto foi o último do conjunto impressionante constituído por aqueles que escreveu (publicados ou inéditos). Oferecemos uma emocionada homenagem a essa contribuição escrita no sofrimento que ela teve de superar para concluir, e por sua contribuição inestimável ao seminário Genre, politique, sexualité(s). Orient/Occident (Fondation Maison des Sciences de l'Homme), do qual participou desde sua criação, dando-lhe uma dinâmica genuína, sem paralelo na pesquisa feminista dentro e fora da França, interessada que era em questões relacionadas a gênero, sexualidade, política, de que tratou mobilizando a filosofia, mas também a psicanálise.

Françoise Collin também havia participado, desde o início, desse seminário e dos anteriores. Quando morreu, fazia quase 15 anos que integrava nosso grupo de trabalho. Ela havia contribuído ativamente no seminário inicial Femmes, culture et politique en France et en Italie, criado para estabelecer trocas bilaterais a partir da Maison des Sciences de l'Homme, quando a Itália era muito pouco conhecida na França no âmbito de uma História das mulheres, entendida no sentido interdisciplinar. No entanto, os trabalhos e a presença de Françoise Collin como pessoa, eram apreciados desde os anos 1980 na Itália, Espanha, Lîbano, Argélia, Tunísia, sem citar o Quebec e a América Latina. Somos gratos a ela por uma contribuição ao mesmo tempo única e plural, ambas, uma "herança sem testamento" (segundo uma expressão de René 
Char que ela gostava de citar), isto é, não ligada a um manual de instruções. Nosso colóquio concebido nesse espírito foi uma experiência aberta ao imprevisto, ao inesperado, longe de qualquer forma de apropriação.

$\mathrm{O}$ anúncio da morte de Françoise Collin se espalhou como rastilho de pólvora em setembro de 2012. Foi dolorosamente experimentado por aqueles que a tinham conhecido, lido, admirado ou criticado, em nosso seminário ou a partir dos seus trabalhos. Naquele momento de emoção compartilhada, iniciativas surgiram simultaneamente, individuais e coletivas, como se o vazio deixado pela amiga, filósofa, feminista, devesse ser preenchido sem demora, mesmo por meio de maneiras a inventar, sob o perigo de que fosse soterrado, com nossa cumplicidade silenciosa, aquilo que todos-as tinham recebido dela ou trocado com ela.

O desejo de prestar-lhe homenagem foi expresso tantas vezes - sob argumentação filosófica, literária ou científica -, do Líbano, da Argélia, da Itália, da Espanha, da França, do Haiti, que pareceu desejável modificar o programa de uma mesa redonda inicialmente prevista com a sua participação, sem alterar seu título: Femmes, genre, féminismes en Méditerranée. Esse encontro foi realizado no Institut d'études européennes (Paris 8 - Saint-Denis) nos dias 28 e 29 de novembro de 2012 na Maison des Sciences de l'Homme, com o apoio de ambas as instituições. O evento reuniu vinte palestrantes de oito países da Europa Ocidental e do Sudeste, do Oriente Médio, do Norte da África e do Caribe. E acabou por adquirir a dimensão de um colóquio internacionalinterdisciplinar, que reuniu mais de trinta participantes (Genre, 2012).

Espontaneamente realizado em torno de Françoise Collin, que se considerava "mulher do Norte", esse colóquio se estruturou a partir do Mediterrâneo. Por quê? Não há nada de paradoxal nisso. A magnitude e a intensidade de seu brilho pessoal, da sua obra e dos Cahiers du Grif em vários lugares da área do Mediterrâneo - no qual não era especialista -, poderiam ter ficado na sombra se não tivéssemos nos encontrado na esteira de sua 
morte: ela despertou em nós um sentimento de vazio e ao mesmo tempo contribuiu para o surgimento de nosso desejo de pensar por nós mesmos, que ela encorajou, sem dizê-lo, na troca e no diálogo mesmo quando em ambiente tenso. ${ }^{5}$

Ela pensava que "o feminismo é principalmente uma revolução do campo simbólico - ideia que compartilhávamos", escreve em sua contribuição Luisa Muraro, filósofa da linguagem, um dos membros fundadores da Librerie delle donne di Milano e da Comunità filosofica femminile-Diotima (Universidade de Verona). Mais adiante, ela cita novamente Françoise Collin: "No político, o simbólico se torna visível e atuante" (Muraro, 2014:241250). O político se obscurece ou transforma-se, em particular no Mediterrâneo oriental, onde guerras cruéis são desencadeadas. Em 2010-2011, as mulheres participaram maciçamente das "Primaveras Árabes". De acordo com Hafida Chekir, professora de direito público na Universidade de Túnis, "Elas puseram abaixo os estudos que afirmavam que as mulheres árabes ainda não tinham ganhado a sua emancipação e que ainda estavam sob o jugo de um patriarca impregnado de sacralidade" (Chékir, 2011). Essa situação inédita nos obriga a reconsiderar numerosas categorias das ciências sociais. Em primeiro lugar, a de "mundo muçulmano" que se revela enganosa quando se ignora a presença dos cristãos no Líbano, na Síria, no Iraque e em outros lugares. Temos também de levar em consideração o recalque de que o Mediterrâneo tem sido objeto na história e na cultura da Europa, em particular no que se refere à emergência da "questão da mulher" no Oriente Médio, desde o início do século XX (Veauvy, 2010).

${ }^{5}$ Pensamos, por exemplo, no colóquio dedicado a La question du 'sujet féminin' entre incertitudes, violences et stratégies de liberté (Maghreb, Europe du Sud' (Paris, 2003). Françoise Collin tinha aceitado presidir a sessão La prostitution entre histoire, débat public et luttes de femmes, que prometia ser tensa e que o foi bem mais do que o esperado. Sua contribuição pessoal nessa sessão se chama "Approche politique de la prostitution: contrat social et contrat commercial" (Azzoug, Rollinde, Veauvy, 2004;249-254). 
Na esteira da experiência surpreendente, e de certa forma "explosiva" (Muraro, 2011:83), que tem sido para nós o simpósio homenageando Françoise Collin, voltamos a ele por intermédio do notável "Ensaio Coletivo de mulheres" publicado sob a direção de Christiane Souriau (arabista, especialista na Líbia, do Centre d'études féminines da Universidade de Aix-en-Provence), com o titulo Femmes et politique autour de la Méditerranée (L'Harmattan, 1980), esquecido de forma curiosamente rápida, talvez por causa da morte prematura daquela cuja iniciativa se encontrava na origem de sua criação. Ela nunca se permitiu deter pela concepção positivista da sociedade barrando o caminho à re-invenção da política e à criação do sujeito, entendendo a subjetivação tal como definida por Alain Touraine como "o chegar ao eu-mesmo como portador de direitos. (...) A ideia de que subjetivação transforma nossa concepção e nossa experiência de nós mesmos e da vida coletiva (...)". Em seu texto "Les femmes et l'argent en Libye. L'économie des femmes" (1986), publicado postumamente, Christiane Souriau vai na contramão do discurso dominante sobre as mulheres no Mediterrâneo (transição linear da tradição à modernidade); em um insight ela incentiva, na fronteira das ciências sociais e da filosofia, a voltar aos primórdios da modernidade e à diferença dos sexos a partir de questóes presentes, superando a oposição entre sujeito e objeto, concreto $e$ abstrato. Luisa Muraro abrirá uma perspectiva mais precisa na mesma direção: "Com o feminismo, de fato, não nos tornamos indivíduos capazes de objetivação do outro mas eliminamos o paradigma sujeito/objeto como tal, chamando o outro a ser o termo de uma relação de intercâmbio" (Muraro, 2004:283).

Reconhecemos com Michelle Perrot, historiadora feminista, que a revolução conceitual iniciada pelo feminismo está longe de ter chegado a todos os seus efeitos. O gênero, por exemplo, não pode ser usado como um conceito pronto em todas as circunstâncias; também não pode ser equiparado a um novo paradigma. Trata-se de uma categoria em constante evolução, que deve ser reexaminada de maneira crítica a cada caso. A fim de determinar em que medida e como a revolução conceitual iniciada 
pelo feminismo, para a qual Françoise Collin foi muito ativa, foi traduzida em nosso colóquio e depois no trabalho coletivo resultante, iremos apresentar agora o livro dele resultante.

Prefaciado por Geneviève Fraisse, filósofa, historiadora do pensamento feminista, ex-delegada interministerial dos direitos das mulheres e ex-deputada europeia, o livro tem uma longa introdução co-assinada por Christiane Veauvy e Mireille Azzoug, 17 contribuições seguidas de um posfácio de Marisa Forcina, professora de história das doutrinas políticas na Universidade de Salento (Puglia), que
aceitou com prazer (...) fornecer (sua) contribuição e (seu) testemunho da proximidade intelectual, filosófica e política, que por mais de vinte anos ligou Françoise Collin à l' Universidade de Salento. Em particular, a um grupo de professores que, nesta universidade, tem representado $e$ incorporado uma maneira de conceber e praticar a filosofia: aberta e dialogal, atento à narrativa da existência, com suas implicações teóreticas e de gênero (p.251).

O livro também inclui uma bibliografia inédita de Françoise Collin (primeira bibliografia de sua obra, tão completa quanto possível), uma nota sobre os Cahiers du Grif, poemas de Françoise Collin e a bibliografia detalhada dos 21 co-autor-es-as.

Chamando o seu prefácio "Pelo curto-circuito", Geneviève Fraisse nos pergunta: "Não era o que tentava Françoise, produzir uma faísca na mente ativa cruzando as coisas da vida com potenciais diversos: política e literatura, filosofia e ativismo?" Se reconhecemos que Françoise Collin trabalhava "como se precisasse sempre deixar a porta aberta para o desconhecido ou o improvável (...) podemos então começar este livro mergulhando na bibliografia no final do volume. É o suficiente para sentir vertigem (...)" (Muraro, 2004:283).

Os textos do nosso volume vão de testemunhos variados a leituras teóricas da contribuição de Françoise Collin, passando pelos estudos históricos de movimentos de mulheres e reflexões filosóficas enraizadas nesses movimentos. Geneviève Fraisse 
propõe quatro chaves de leitura: a troca, o percurso, o eu-sujeito, o simbólico, para ajudar a entrar em um trabalho que inclui livros, numerosos artigos e contribuições para obras coletivas (hoje dispersas) e uma parte volátil correspondente a intervenções orais $e$ a inúmeras discussões e intercâmbios dos quais Françoise Collin dedicou parte da sua vida.

Femmes, genre, féminismes en Méditerranée tem origens plurais, como salientou a introdução. No desejo partilhado de manter vivo o pensamento de Françoise Collin, voltamos a considerar trabalhos realizados na França ou a partir da França no que diz respeito a nossa problemática em gestação, especialmente com o ensaio coletivo Femmes et politique autour de la Méditerranée (1980) que mantém um caráter efervescente de atualidade tanto no campo prático quanto no teórico. Temos por prova as semelhanças reconhecíveis entre a Itália e o Líbano no que se refere às criticas realizadas pelas feministas sobre a política realmente existente.

Os trabalhos disponíveis sobre o Mediterrâneo confrontados às mudanças radicais recentes no mundo árabe nos orientam para uma redescoberta do simbólico e da troca considerados do ponto de vista da passagem da troca de mulheres para a troca entre mulheres - título de uma contribuição de Françoise Collin no seminário ítalo-francês realizado em 2007 na Universidade de Verona pela comunidade filosófica feminina Diotima (Collin, 2007).

As contribuições foram agrupadas em três partes, a fim de abrir melhor caminhos de reflexão. A primeira, intitulada "Féminismes et politiques des femmes en Méditerranée. Expériences transméditerranéennes", se abre com a contribuição de Françoise Duroux, segundo a qual ao Norte o gênero "enquadra a reflexão feminista expulsando o sexual", enquanto que no Sul os feminismos estão mais enraizadas em um projeto sexual. Esses movimentos são estudados por Azadeh Kian (Oriente Médio), Evelyne Accad (Lîbano, Egito) e Fériel Lalami (Argélia). Stefania Ferrando, ativa na Itália no pensamento da diferença $e$ na política das mulheres, parte da leitura da revolução iraniana por Michel Foucault e se pergunta se não haveria ali "um ponto de 
possível emergência de novas ideias". Rada Ivekovic examina a questão da identidade, particularmente a do Mediterrâneo "que a Europa não soube nem pensar nem gerenciar".

Carmen Boustani introduz a segunda parte, "Françoise Collin: um percurso singular", retornando à sua obra literária desconhecida na França e que ela conecta à sua jornada feminista. Mireille Azzoug restaura precisamente Françoise Collin como "feminista livre". Marta Segarra faz um balanço dos estudos sobre as mulheres na Espanha mostrando a influência do pensamento de Françoise Collin naquele país. Alain Naze e Eleonora Missana fazem a abordagem da sua obra como filósofos: o primeiro intitula sua contribuição "Françoise Collin ou a alteridade como a alteração de si mesmo", considerando que seu esforço teórico consistiu, sobretudo, tal como ele percebe a partir de seu livro Parcours féministe, em combater o reino da identidade; a segunda abre a perspectiva que explicita seu título, "Desfazer o sujeito, tecer laços inesperados. Com Françoise Collin".

"Leitura e prolongamentos de um caminhar para o que ainda não é" é o título da terceira parte, que reúne contribuições de Fina Birulès ("Françoise Collin, praxis da diferença e mundo plural"), de Nadia Setti ("Escrever, pensar, criar: modalidades $e$ práticas do agir"), de Mara Montanaro e Sylvia Duverger ("A práxis do pensamento: Françoise Collin, filósofa e feminista"), de Laennec Hurbon ("Françoise Collin, leitora de Hannah Arendt. Notícias e limites do pensamento de arendtiano") e de Luisa Muraro ("Ouvindo Françoise Collin: o preço pago e a pagar pela exclusão das mulheres").

A publicação da totalidade das contribuições se impôs no final desse colóquio como um desejo impossível de não ser considerado em uma perspectiva material, intelectual, política, aberta à divulgação dos resultados e intercâmbios que nasceriam, no Mediterrâneo e além, particularmente no Brasil. Longe da obsessão pelo acúmulo indiferenciado de conhecimentos relacionados com a descoberta do itinerário e da obra de Françoise Collin, a originalidade dos trabalhos se situa, longe de 
qualquer incentivo à concorrência entre interventores-as, na possibilidade oferecida a cada um-a de, a partir de si e da sua experiência, que inclui a relação com Françoise Collin, estabelecer trocas entre mulheres e homens interessados em criar uma nova forma de pensar, por caminhos distantes dos imperativos acadêmicos (oposição de uma teoria a outra, dissociação entre teoria e prática, etc.). "Viver (este percurso que é chamado de movimento de mulheres e tomada de consciência feminista) $e$ fazer disso narrativa, arte, conhecimento e ciência" assim poderia ser nosso horizonte para "tornar históricas as experiências subjetivas porque estas são eventos que atuam no real" (Muraro 2011:33).

\section{Referências bibliográficas}

Azzoug, Mireille; Rollinde, Marguerite; Veauvy, Christiane (dir.). Les femmes entre violences et stratégies de liberté. Maghreb et Europe du Sud. Paris, Editions Bouchène, 2004.

Azzoug, Mireille; Veauvy, Christiane (org.). Femmes, genre, féminismes en Méditerranée. 'Le vent de la pensée'. Hommage à Françoise Collin. Saint-Denis, Editions Bouchène, 2014.

CHEKIR, Hafidha. Le combat pour le droit des femmes dans le monde arabe conferência apresentada na Maison des Sciences de l'Homme em 2011 [http://halshs.archives-ouvertes.fr/FMSH-WP/halshs01005544 - acesso em: 05 mar. 2016].

Collin, Françoise. Anthologie québécoise, 1977-2000. Editora MarieBlanche Tahon. Montréal, Les éditions du remue-ménage, 2014.

Collin, Françoise. De l'échange des femmes à l'échange entre femmes. 2007 [www.diotimafilosofe.it/down.phpt=3\&id=156 - acesso em: 22 abr. 2016].

COLLIN, Françoise. Féminisme contemporain et espace public. In: VEAUVY C. (dir.) Les femmes dans l'espace public. Itinéraires français et italiens. Editions de la Maison des Sciences de l'Homme / Le fil d'Ariane, Saint-Denis, Université Paris 8, 2004, pp.49-55 
COLLIN, Françoise. Le féminisme et la crise du moderne. In: LAMOUREUX, Diane. Fragments et collages. Essai sur le féminisme québécois des années 70. Montréal, Remue-ménage, 1986, pp.7-16.

COLLIN, Françoise. Le féminisme: une démarche politique. Entrevista a Ghila Benesty-Sroka para La Parole métèque (6), 1988, pp.139-147.

Collin, Françoise. Praxis de la differencia: liberacion y libertad. Editora Marta Segarra. Barcelona, Icaria editorial/Zaragoza, Prensas universitarias di Zaragoza, 2006.

COLLIN, Françoise. Quarante ans de recherche sur les femmes, le sexe et le genre : Françoise Collin. Palestra no Auditório da Grande Galerie de l'évolution du Musée national d'histoire naturelle, 2011 (77mm, filmado pelo Centre audiovisuel Simone de Beauvoir) [ $<$ http://www.dailymotion.com/video/xih7ph_conference-defrancoise-collin-19-mars-2011 school - acesso em: 21 abr. 2016; e http://www.institutemilieduchatelet.org/details-recapitulative-desconferences?id=79 - acesso em: 21 abr. 2016].

DUVERGER, S.; MONTANARO, M. La praxis de la pensée : Françoise Collin, philosophe et féministe. In: AzzOUG, Mireille; VEAUVY, Christiane, (org.). Femmes, genre, féminismes en Méditerranée. 'Le vent de la pensée!. Hommage à Françoise Collin. Saint-Denis, Editions Bouchène, 2014, pp.209-228.

GENRE, politique, sexualité(s). Orient/Occident (Fondation Maison des Sciences de l'Homme) [http://www.archivesaudiovisuelles.fr/2233/ acesso em: 2 abr. 2016].

HAASE-DUBOSC, D.; ROCHEFORT, F. Entretien avec Françoise Collin. Philosophe et intellectuelle féministe. Clio. Histoire, femmes et société, $\mathrm{n}^{\circ} 13$, pp.195-210 [http://clio.revues.org/1545 ; DOI : 10.4000/clio.1545 - acesso em: 2 de abr. 2016].

LAMY, Suzanne. Françoise Collin: la diversité des pratiques. Spirale (53), 1985, pp.83-86.

Muraro, Luisa. Non é da tutti. L'indicibile fortuna di nascere donna. Roma, editore Carocci, Le sfere 57, 2011.

MURARO, Luisa. En écoutant Françoise Collin: le prix payé et à payer pour l'exclusion des femmes. In: Azzoug, Mireille; VeAUVY, Christiane (org.). Femmes, genre, féminismes en Méditerranée. 'Le vent de la 
pensée!. Hommage à Françoise Collin. Saint-Denis, Editions Bouchène, 2014, pp.241-250.

Muraro, Luisa. Du féminisme à la politique des femmes. In: VEAUVY, C. (dir.). Les femmes dans l'espace public. Itinéraires français et italiens. Editions de la Maison des Sciences de l'Homme / Le fil d'Ariane, Université Paris 8, Saint-Denis, 2004, pp.279-290.

TOURAINE, Alain. La fin des sociétés. Paris, Le Seuil, 2013.

VEAUVY, Christiane (ed.) Genre, politique, sexualité(s). Europe/Orient. International Review of Sociology/Revue Internationale de Sociologie, vol. 20, n² , julho 2010, pp.255-376.

VVAA. Les femmes et l'argent. Actes du colloque pluridisciplinaire et international. Editora Christiane Souriau. Aix-en-Provence. Centre d'études féminines de l'université de Provence, 1986. 